Meulenkamp, T.M., Gevers, S.K., Bovenberg, J.A., Koppelman, G.H., Hylckama Vlieg, A. van, Smets, E.M.A. Communication of biobanks' research results: what do (potential) participants want? American Journal of Medical Genetics: Part A: 2010, 152A(10), 2482-2492

\begin{tabular}{|l|l|}
\hline Postprint Version & 1.0 \\
\hline Journal website & $\underline{\text { http://dx.doi.org/10.1002/ajmg.a.33617 }}$ \\
\hline Pubmed link & $\underline{\text { http://www.ncbi.nlm.nih.gov/pubmed/20799322 }}$ \\
\hline DOI & 10.1002/ajmg.a.33617 \\
\hline
\end{tabular}

This is a NIVEL certified Post Print, more info at http://www.nivel.eu

\title{
Communication of Biobanks’ Research Results: What Do (Potential) Participants Want?
}

\author{
TineKe M. MeulenKamp, ${ }^{1}$ SJef K. GeVers, ${ }^{2}$ Jasper A. Bovenberg, ${ }^{2}$ Gerard H. Koppelman, ${ }^{3}$ Astrid \\ VAN HYLCKAMA VLIEG, ${ }^{4}$ AND ELLEN M.A. SMETS ${ }^{1 *}$
}

${ }^{1}$ Department of Medical Psychology, Academic Medical Center/University of Amsterdam, Amsterdam, the Netherlands

${ }^{2}$ Department of Social Medicine, Academic Medical Center/University of Amsterdam, Amsterdam, the Netherlands

${ }^{3}$ Department of Paediatric Pulmonology and Paediatric Allergology, Beatrix Children's Hospital, University Medical Center Groningen, University of Groningen, Groningen, the Netherlands

${ }^{4}$ Department of Clinical Epidemiology, Leiden University Medical Center, Leiden, the Netherlands

The aim of this study was to investigate (potential) research participants' (a) information preferences with regard to receiving biobanks' genetic research results, and (b) attitudes towards the duties of researchers to communicate research results.Atotal group of 1,678 was analyzed, consisting of a sample of the general Dutch population $(\mathrm{N}=1,163)$ and patients with asthma, rhinitis, and thrombosis $(\mathrm{N}=515)$ who completed a survey including six fictitious genetic research results each presented as aggregate and individual result, varied for treatability and kind of disease. Five questions assessed attitudes towards researchers' duties to communicate research results. Additionally, background characteristics were measured. A majority of the respondents wanted to receive aggregate results as well as individual results. A small majority (59\%) held the view that researchers should communicate individual results with no health consequences. One third agreed with an information duty only when treatment is available. A preference for individual results and an attitude in favor of communicating results were both associated with belonging to the general Dutch population rather than being a patient, wanting to learn about own health as the reason for biobankparticipation, a monitoring coping style, a general desire for health information, perceived meaningfulness of genetic information and no anticipated anxiousness. A sizable majority of respondents showed a high information preference for individual results, even when it is unclear that treatment is available. Fewer were of the opinion that researchers should make this possible. For their communication policy biobanks should take notice of (potential) participants' high information preferences and expectations. _ 2010 Wiley-Liss, Inc. Key words: information preference; biobank; disclosing results

\section{INTRODUCTION}

One of the challenges in the post-genomics era is the research on common complex disorders. This research is aided by biobanks, organized collections of biological samples and associated data, that differ in 
Meulenkamp, T.M., Gevers, S.K., Bovenberg, J.A., Koppelman, G.H., Hylckama Vlieg, A. van, Smets, E.M.A. Communication of biobanks' research results: what do (potential) participants want? American Journal of Medical Genetics: Part A: 2010, 152A(10), 2482-2492

scope from small collections in academic or hospital settings to large-scale national repositories [CambonThomsen, 2004]. Biobanks yield many different research results. To what extent research participants need to be informed about research results and to what extent researchers have a duty to communicate such information is the subject of much debate [e.g., Knoppers et al., 2006; Ravitsky and Wilfond, 2006; Wolf et al., 2008; Bovenberg et al., 2009]. Biobanks may generate results at various stages: results of the initial health measurements at enrollment (e.g., blood pressure, cholesterol); results of biochemical measurements of the samples taken (e.g., liver functioning and genetic tests) and, finally, research results on the relation between genes, environment, and illnesses. The latter can be aggregate research results, representing synthesized data and conclusions drawn from groups of research participants, or individual research results, representing distinct items of data collected from or about individual participants [Shalowitz and Miller, 2005]. Aggregate results can be interpreted as personally relevant by participants [Miller et al., 2008]. There may be unexpected, incidental, findings, that is, findings that are discovered in the course of conducting the research but which are beyond the aims of the study in question [Wolf et al., 2008]. Several authors conclude that researchers in general have the ethical or moral duty to communicate the so called aggregate research results to the participants [Beskow et al., 2001; Partridge and Winer, 2002; Fernandez et al., 2003]. However, it has been argued that decisions about the communication of individual research results of biobanking should be based upon a case-by-case approach. Whether individual research results should be communicated is dependent on the analytical validity (accuracy and reliability of the DNA variant determination), clinical utility (the result leads to improved participants' well-being), context of the study (e.g., the availability of the right person to communicate results, alternative access to results, costs involved, relationship between the researcher and participants, expectations raised by the biobank), and potential negative financial impact on the participant (i.e., insurance) [Knoppers et al., 2006; Ravitsky and Wilfond, 2006; Bovenberg et al., 2009]. Though the communication policy is clear for research results with evident health implications for a participant, expected or unexpected, biobanks ordinary yield many research results with less evident significance for health but which might be experienced as relevant by an individual. Predictions can already be made for small groups of people with a somewhat higher or lower chance than the average population, for instance concerning the risk of developing type II diabetes [van Ommen and Cornel, 2008]. However, we are steps removed from clinical applications of genome wide association studies [Pearson and Manolio, 2008], though results of these studies may contribute to establishing a risk profile when multiple genetic risk factors are combined with known predictive factors such as family history, which holds promise for clinical application, for instance for asthma [Koppelman et al., 2008]. Many biobanks have the policy to communicate only results of measurements taken at enrollment and incidental findings with high clinical significance. Other research results are not communicated for reasons including (a) that most research findings involving biobanks are aggregate findings of an exploratory nature, with little or no analytical validity or clinical utility for the individual concerned, (b) the costs, competence, and complexity involved in proper reporting to individuals, and (c) that these findings are difficult to be linked to identifiable participants [Beskow et al., 2001; Knoppers et al., 2006; Cambon-Thomsen et al., 2007; Boggio, 2008]. The question is whether the existing policy will hold for the future. As participants take part in a biobank for a long time, continuously providing the biobank with new health information, they may expect something in return. Moreover, the accumulation of data and new technologies may lead to new research results with, eventually, clinical significance. For the continuing discussion on the issue of the communication of individual research results to participants of biobanks, it is important to know the opinion of (potential) participants. In a study by Murphy et al. [2008] focus groups revealed a strong desire of potential participants to be able to access individual research results of a biobank. A review including 28 empirical studies concerning communication of research results (7 of which concerned genetics research) found that a median of $90 \%$ (range 20-100\%) of participants wished to receive any study results [Shalowitz and Miller, 2008]. Only few of the studies focused on the communication of research results of biobanks and few give insight in the factors that influence information preference in receiving results. We therefore conducted a study with the aim to investigate the (potential) research participants' information preferences with regard to receiving various kinds of biobanks' research results and the background characteristics that affect information preferences. We investigated the research question in the general Dutch population as well as in patients who participated in genetic research. We also investigated the opinion of (potential) participants about the duty of researchers to communicate research results and the background characteristics that are associated with this opinion. 


\section{METHODS}

\section{Participants and Procedure}

The study-design involved a cross-sectional survey, which was sent to a sample of the general Dutch population and to patients. For the sample of the general Dutch population, the Dutch Health Consumer Panel of the Netherlands Institute for Health Services Research (NIVEL) was used. This panel is representative for the Dutch adult population regarding age and sex [de Jong et al., 2008; www.nivel.nl] and represented in our study potential research participants. Patients were recruited via two family studies on asthma and one family study on rhinitis, including only probands, of the University Medical Center Groningen(UMCG) [Jongepier et al., 2005; Postma et al., 2005; Reijmerink et al., 2008]. Additionally, patients with arm-thrombosiswere recruited from theMEGAstudy at the Leiden University Medical Center (LUMC), including some patients with venous thrombosis of the THE-VTE-study [Rosendaal et al., 2007; Flinterman et al., 2008]. All patients had previously given consent to donate blood or saliva samples for long-term scientific research on the relation between genes and disease. They were informed that they would not receive research results on an individual level, with the exception of the measurements at the enrolment. However, they were informed they would receive aggregate research results, which actually has been done by means of meetings (UMCG) and/ or newsletters (LUMC, UMCG). Participants of the Dutch Health Consumer Panel received our survey via the NIVEL, patients via the respective departments of the UMCG and LUMC. Patients' surveys were accompanied by an invitation letter of the principal investigator responsible for the biobank study in which they were enrolled. A reminder letter was sent 2 weeks later. The Medical Ethics Committees (MEC) of the Academical Centers provided an exemption for the study to seek formal approval.

\section{MEASURES}

To develop the survey we carried out two focus group interviews with healthy individuals $(\mathrm{N}=9)$ and with patients $(\mathrm{N}=7)$. We also interviewed researchers $(\mathrm{N}=11)$ who were project-leader of a biobank, including small collections in academic hospitals and large-scale repositories. The interviews aimed to detect issues relevant for the communication of biobank research results and to learn the level of understanding about these issues. The survey comprised questions regarding respondents' (a) information preferences in receiving aggregate and individual research results, (b) attitudes towards the duty of researchers to communicate such research results, and (c) background characteristics. Most questions were formulated as statements with a fivepoint response scale assessing respondents' degree of agreement.An initial version of the survey was piloted with eight persons. Information preferences for receiving research resultswere assessed using six aggregate fictitious research results related to genes (see for the items in Table II). Respondents were instructed to fill in the questions assuming they would contribute to a biobank, described as "long-lasting health research on genes and environment." The results were formulated as " chanceresults," e.g., "research shows that people who have a specific mutation in their genes have a somewhat higher chance of getting stomach cancer than people who do not have this mutation.' It was explained that "a somewhat higher chance" meant a chance that is $1-5 \%$ higher. No further explanation was given about the interpretation of these chances. The six fictitious results were formulated such that they addressed the relation between a genemutation and (1) a heightened chance of getting a disease, varied for the possibility of treatment to lower this chance, (2) a heightened chance that a specific medication would work well, varied for the situation that one had the disease or not, and (3) the heightened chance of a worse course of a disease, also varied for the situation that one had the disease or not. To also vary the seriousness of the consequences, all six results related to stomach cancer (serious consequences) and to high blood pressure (less serious consequences), respectively. For the patients, results also addressed their own disease (asthma, rhinitis, or thrombosis). Following the presentation of each fictitious result, respondents were first asked to indicate if they would like to be informed about the aggregate result, described as "I would like to receive this general information"' (referred as the "aggregate result"). Secondly, they were asked to indicate whether they wanted the result individualized, described as "I would like to be informedif I have the mutation in the gene”' (referred as the "individual result"). Both questions had a five-point scale 
Meulenkamp, T.M., Gevers, S.K., Bovenberg, J.A., Koppelman, G.H., Hylckama Vlieg, A. van, Smets, E.M.A. Communication of biobanks' research results: what do (potential) participants want? American Journal of Medical Genetics: Part A: 2010, 152A(10), 2482-2492

(definitely not (1), definitely yes (5)). All scores regarding the respondents' preference for aggregate results were summed. Subsequently, a mean score for the scale "aggregate results" was calculated (six items, Cronbach's a $=0.96$, range $1-5$ ). The same procedure was followed for the items concerning respondents' preference to know their carrier status, resulting in a scale “individual results” (12 items, Cronbach's $\mathrm{a}=0.97$, range 1-5). We made subscales measuring information preferences for results varying in availability of treatment, whether one had the disease or not and seriousness of the consequences (see Table II). All subscales had satisfactory internal consistencies as indicated by Cronbach's alpha of 0.89 or higher. We asked respondents how they would like to be informed about the aggregate results and by whom they would like to be informed about the individual results, using fixed responses. Attitudes on the duty of researchers tocommunicate research results were assessed using five items (see Table III). Item scores were summed and a mean score was calculated for " attitudes on researchers' duties" (Cronbach's a $=0.72$, range 1-5). The higher the score, the more respondents believed that researchers ought to communicate various kinds of biobank research results. Background characteristics: The following sociodemographic variables were assessed: age, sex, having children, level of education, ethnicity, religiousness, employment in healthcare, being involved with genetics or biotechnology, and chronic illness. We measured respondents' perceived general health: "'how would you describe your general health?” (very well (1), bad (5)) and the degree that they were bothered by their illness ((1) not at all, very much (7)). A scale about health-related lifestyle was used including six questions with a five-point response scale: consciousness of health, importance of good health, the degree of concern with health, doing something healthy on a daily basis, eating as healthy as possible, exercising as much as possible [Pin, 2009] (Cronbach's a=0.88, range 6-30). Participants of the Dutch Health Care Consumer Panel were asked whether they or a family member had been genetically tested, whether they had contributed to a biobank in the past or would be willing to do so in the future (yes, no, do not know yet) and their reason for (future) contribution. Patients received the latter question as well. Answers included "altruistic" reasons (two items), to obtain "health and treatment information"' for themselves or family members (two items), and 'because the researcher asks me"' (one item) (see for the items in Table V). The following psychological characteristics were assessed. To measure the respondents' tendency to actively search for medical information, the short version of the monitoring scale of the Threatening Medical Situations Inventory (TMSI) was used [van Zuuren et al., 1996; Ong et al., 1999]. It consists of descriptions of two threatening medical situations ("vague suspicious headachecomplaints"' and 'choosing for uncertain heart surgery”'). Respondents had to answer on a fivepoint Likert scale to what degree they will be: (a) looking for information within the threatening situation; (b) going deeply into the situation by reading it out; and (c) getting information about the situation from other doctors, patients, or organizations ( 6 items, Cronbach's a $=0.79$ ). Total scores were summed up (range 6-30), higher scores indicated a higher tendency to actively search for information in case of medical threat. Respondents' general preference for information about illnesses and treatment ("'how much do you want to know in general about illnesses and treatment?") was measured with a Likert scale from 0 (as little as possible) till 10 (as precise as possible) [Cassileth et al., 1980]. To measure respondents' general trust in doctors we used an adapted short version of the WakeForest Physician Scale [Dugan et al., 2005; Franssen et al., 2009]. Respondents indicated how much faith they had in physicians in general when it comes to (a) putting their patients' interests first, (b) being precise and careful, (c) decisionmaking about medical treatment, (d) informing their patients honestly, and (e) their overall conclusion about their trust in physicians. Answers ranged from "totally disagree" (1) to "totally agree" (5). Scores were summed up with higher scores indicating higher trust (Cronbach’s a $=0.82$ ). Finally, we asked for respondents' perception of: (a) ownership regarding their blood after donation to a biobank, (b) privacywhen information on gene mutation becomes available, (c) consequences of disclosure of carrier status for insurance, (d) the possible meaningfulness of results on gene mutation for the health of family or children, and (e) anticipated anxiety upon receiving results regarding gene mutation (see for the items in Table V). These topics had emerged from the focus groups as relevant for the communication of research results.

\section{[TABLE 1]}




\section{Statistical Analysis}

Sample characteristics of participants of the Dutch Health Care Consumer Panel and patients were compared using t-tests and chisquared tests. The data of the two groups were combined for subsequent analyses. Differences between scores on the subscales concerning information preferences were tested using pairedsamples t-tests. The influence of background characteristics on the scores for the scales "individual results"' and "attitudes on researchers" duties were investigated using regression analysis. Belonging to the group of the Dutch Health Care Consumer Panel or patients was treated as a background characteristic. Variables that were significant at $\mathrm{P}<0.025$ and sociodemographic variables (sex, age, and education) were taken into a multiple linear regression model simultaneously (method ENTER). Variables with P-value $>0.05$ were removed one by one, sociodemographic variables were left in the analyses. Finally non-significant sociodemographic variables were removed and variables that were significant at $\mathrm{P}<0.05$ remained. The statistical program SPSS 15.0 for Windows was used for the analyses.

\section{RESULTS}

\section{Sample Characteristics}

The total sample comprised 1,678 respondents: 1,163 participants of the Dutch Health Care Consumer Panel (response 78\%) and 515 patients (response 53\%) returned the survey. Sample characteristics are presented in Table I. Participants of the panel were older and more often religious than patients $(\mathrm{P}<0.001)$. Responding participants of the panel were older $(m=55.7)$ than nonresponding participants of the panel $(\mathrm{m}=49.8)(\mathrm{P}<0.001)$. No such non-response analyses could be performed for the patient group.

\section{INFORMATION PREFERENCES}

\section{Preference for aggregate results.}

For the individual items comprising the "aggregate results"' scale ( $\mathrm{m}=4.0$, s.d.=1.09), a majority of 70 $78 \%$ of the respondents would "probably" or "definitely" like to receive the aggregate results (Table II). A minority of 13-17\% did "probably" or "definitely" not want to receive the aggregate results. Respondents preferred to receive the aggregate results via information letters (41\%), at meetingswhere results are orally explained (19\%), via a website on the internet (12\%), articles in newspapers or magazines (4\%), or scientific articles (3\%). Almost one-fifth (17\%) had no preference. Preference for individual results. Respondents scored slightly higher on the "individual results" scale $(m=4.1$, s.d. $=0.9)$ than on the “aggregate results"' scale $(\mathrm{m}=4.0$, s.d. $=1.1)(\mathrm{P}<0.001)$. Concerning the individual items, a majority of 66$88 \%$ of the respondents would "probably" or "definitely" like to be informed if they had the mutation in the genes themselves, whereas a minority of 5-20\% would " probably" or "definitely" not like to be informed (Table II). Respondents preferred information on (a) the chance of getting a disease $(\mathrm{m}=4.2$, s.d. $=1)$ over information about medicationuse $(\mathrm{m}=4.1$, s.d. $=1)$ and worse course of a disease $(\mathrm{m}=4.0$, s.d.=1.0) $(\mathrm{P}<0.001)$, (b) the situation where treatment is known to lower the chance of getting a disease $(\mathrm{m}=4.3$, s.d. $=1)$ over the situation where the effect of treatment is unknown $(\mathrm{m}=4.2, \mathrm{s.d} .=1.0)(\mathrm{P}<0.001)$, (c) results for medication-use and course of the disease in the case they have the disease $(\mathrm{m}=4.3$, s.d. $=0.9)$ over the situation that they do not have the disease $(m=3.9$, s.d. $=1.2)(P<0.001)$, and $(d)$ results on high blood pressure $(\mathrm{m}=4.2$, s.d.0.9) over stomach cancer $(\mathrm{m}=4.1$, s.d. $=1)(\mathrm{P}<0.001)$. Finally, patients were more eager to receive results on their carrier status relating to their own disease $(\mathrm{m}=4.3$, s.d. $=1)$ compared to their preference for such information on high blood pressure $(\mathrm{m}=4.1$, s.d. $=1.0)$ or stomach cancer $(\mathrm{m}=4.0$, s.d.=1.0) $(\mathrm{P}<0.001)$. Respondents preferred to be informed about individual results by a physician connected to the research (34\%), the family doctor (25\%), own physician (14\%), the researchers themselves $(8 \%)$, or a genetic counselor (6\%). Two percent wanted to have the ability to look at the results themselves.

\section{Attitudes About the Duty of Researchers to Communicate Research Results}

The mean score on the attitude scale is 3.9 (s.d.=0.8), indicating that respondents in general agree that researchers have the duty to communicate various kinds of research results. Participants of the Dutch Health Care Consumer Panel had a higher mean score $(m=3.9)$ than patients $(m=3.7)(P<0.001)$ (scores on individual items are shown in Table III). Most respondents (85\%) agreed with the statement that researchers 
must inform biobank research participants about general research results (Table III). A majority of the respondents (59\%) also was of the opinion that researchers have the duty to inform participants about a mutation in their genes, even when the consequences for their health are not clear yet. Over one-third (37\%) of the respondents indicated that researchers only have such a duty when treatment is available. Only $9 \%$ considered it justified when research participants do not receive any information about their individual gene mutations. Finally $74 \%$ of the respondents agreed that researchers should spend extra effort on informing research participants about a mutation in their genes, even when this would cost extra money.

\section{Influence of Background Characteristics}

Background characteristics affecting information preferences for gene mutation information and attitudes on researchers' duties towards the communication of research results are presented in Table IV.

Descriptives concerning other background characteristics, apart from the sample characteristics presented in Table I, are presented in Table V. Information preference for individual results. Participants of the panel had a higher information preference than patients. Older respondents had a higher information preference ${ }^{1}$. Respondents who would contribute to a biobank to learn about their own health or because they were asked by the physician/researcher, scored higher, respectively, lower on receiving individual results than the respondents who would contribute to a biobank for altruistic reasons (i.e., contribute to science or to be meaningful for others).A monitoring coping style (the tendency to actively search for medical information) and a general desire for information about illnesses and treatment were positively associated with information preference. Respondents who stronger believed that information about gene mutations is meaningful for children or family, preferred more information. Respondents who considered gene mutation information as potentially frightening, had a lower information preference. Within the group of participants of the panel, a difference in information preference was found between those who did not want to contribute to a biobank in the future ( $m=3.5$; s.d. 1.2), did not know (yet) $(m=4.2$; s.d. 0.8$)$ or did want to contribute $(\mathrm{m}=4.4$; s.d. 0.8) $(\mathrm{P}<0.001)$. Attitudes on researchers' duties to communicate research results. Participants of the Dutch Health Care Consumer Panel believed stronger than patients that researchers have a duty to communicate research results (Table IV). Women more often than men endorsed this statement. Respondents who would want to participate or had participated in genetic research to learn about their own health scored higher than respondents who would want to participate or had participated in a biobank for altruistic reasons. Attitudes on researchers' duties were also positively associated with a monitoring coping style, a general desire for information about illnesses and treatment and perceived meaningfulness of gene information for children or family. Attitudes were negatively associated with anticipated anxiousness upon receiving information. The more respondents agreed with the statement that privacy will be harmed if gene mutation information becomes available the lower their score on attitudes on researchers' duties. Finally, the more respondents believed that participants retain ownership over their blood, the higher their score.

\section{DISCUSSION}

\section{Information Preferences}

We found that a majority of the respondents wanted to receive aggregate and individual research results of biobanks. This finding is consistent with other studies. Potential participants of a national biobank had a strong desire for individual research results [Murphy et al., 2008]. Other studies reveal a high information preference to know genetic predisposition [Hoeyer et al., 2004], results of genetic research with stored biological samples [Fong et al., 2006], or results of clinical trials [Partridge et al., 2003, 2005], even with unclear significance [Wendler and Emanuel, 2002]. Of note is that while many respondents in our study wanted to receive aggregate as well as individual results, they preferred the individual results slightly more. This finding is supported by a qualitative study where participants were also more interested in receiving individual genetic test results than aggregate results [Kaphingst et al., 2006]. The question is why respondents in our study showed such a high information preference. Respondents in a study by Wendler and Pentz [2007] indicated that the collection of test results on Alzheimer disease and cancer increased their desire to know the results because they did not want investigators to have information they had not. We encountered this argument also in our preparatory focus groups; the mere existence and perceived availability of data supported respondents' desire to have them. In a study on (genetic) health information, the general population expressed a right to choose whether to know health risk information and to 
controlwho else knows [Diergaarde et al., 2007]. Another argument raised in our focus groups was that a result might be meaningful to them "at some unforeseen point in time" and respondents did not want to have the feeling they "'missed"' it. Such anticipated feelings of regret are known to motivate genetic testing [e.g., Brodersen et al., 2004]. Anticipated regret may explain why we found many respondents wanting toknow research results on medication-efficacy and course of disease, even if they themselves did not have the disease of concern. The high information preference is remarkable as it concerned relatively small heightened chances (1-5\% higher). However, we know that patients are interested in information about very low risks [Janssen et al., 2009]. Though a majority of respondents wanted to receive all kind of research results, a sizable minority did not want to receive aggregate results (range 13-17\%) or individual results (range 5-20\%). Apart from individuals who probably do not want to be informed whatsoever, the wider range of scores for gene mutation results indicates that information preference is dependent on the kind of result. We indeed found such variation in information preference. Respondents were less willing to know their mutation status when (a) it is unknown whether treatment is available, (b) they do not have the disease the result relates to and (c) when it concerns a more serious disease (stomach cancer). Likewise, in the study by Hoeyer et al. [2004], 55\% indicated that they would like to know genetic predispositions only if some kind of treatment or preventive intervention was available. Murphy et al. [2008] found in their focus groups that potential participants were mixed in their information preference in case of an untreatable condition (Alzheimer disease), whereas most focus group members wanted to receive results for a treatable condition (asthma). These findings suggest that individuals prefer more information when the condition of concern is controllable and not too threatening.

\section{[TABLE 2]}

\section{[TABLE 3]}

\section{Attitudes on Researchers' Duties Towards the Communication of Research Results}

A vast majority of the respondents agreed that researchers should communicate aggregate research results. Likewise, only 9\% would approve when no information on gene mutation would be provided. However, a group had the opinion that not all gene mutation results should be communicated. More than one third of the respondents took the view that researchers only have to communicate results when treatment is available. Clinical significance is an important argument in the debate on the communication of research results of biobanks. Our findings indicate that for (potential) participants not the health consequence per se, but the possibility of treatment is the most important argument in this regard.

\section{Influence of Background Characteristics}

Patients, compared to the Dutch population, were slightly less strong in their information preference in receiving individual research results and in their opinion that researchers have a duty to inform. All patients were told that they would not be informed about individual results as part of the informed consent procedure of the biobank they contributed to. We hypothesize that they were more informed than the general Dutch population about the (im) possibilities of the communication of research results and therefore had somewhat lower scores than patients. The reason to contribute to (future) biobanks was associated with the information preference: respondents who (would) donate mainly for altruistic reasons wanted less information about results and were less inclined to have the opinion that researchers have a duty to communicate results. Multifactorial diseases are caused by a complex interplay of several genes and the environment and thus, contrary to monogenetic diseases, consequences for relatives are not so obvious. Nevertheless, most respondents took the view that knowledge of a gene mutation as a result of biobank participation could be meaningful to children and other relatives. Indeed, Dixon-Woods et al. [2007] also found respondents to indicate that when talking about "genes" they thought that this information had implications for their children. We found the perceived meaningfulness for children and/or family to be highly associated with information preference and attitudes concerning researchers' duties. Perceived anxiousness was related to lower information preference and was negatively associated with attitudes about the duties of researchers to communicate research results. Increased anxiety was actually found in about a 
quarter of study participants when confronted with results of a clinical trial about treatment [Partridge et al., 2009]. The same amount of patients reported feelings of anxiety when confronted with increased risk on second cancers [Schulz et al., 2003]. However, most participants in these studies indicated that they wanted to receive the offered results. The background characteristics "employed in health care" and "involvement in biotechnology or genetics"' did not contribute to the variation in information preference and attitudes on researchers' duties. Cautiously we may conclude that knowledge of genetic risk information apparently does not contribute to the variation in information preference.

\section{Limitations}

Some study limitations deserve to be mentioned. First, we spent much effort in developing the questionnaire to do justice to the complexity of the issues involved. Our questionnaire seemed relevant as suggested by the satisfactory response rate. Moreover, we found higher scores on information preferences and attitudes for respondents who had a tendency to actively search for information in case of medical threat (monitoring coping style) and thosewith a high general desire for health information. This is consistent with the literature [e.g., Wakefield et al., 2007; Janssen et al., 2009] and supports the validity of our approach. In our pilot most respondents understood the meaning of an individual result; they understood that, in case they had a gene mutation, they would not necessarily have the same heightened chance (1 till 5\%) on getting a disease, as other factors are involved. However, respondents may have had difficulty to fully understand the fictitious results as we are aware that people in general have difficulty understanding genetic risk information [Bogardus et al., 1999; Edwards et al., 2001; Michie et al., 2005]. Besides, respondents were not informed in our study about the full diversity of research results that come from research of biobanking. Most research results of biobanks cannot be described in terms of health outcomes, such as results demonstrating an association between a gene variant and an intermediate metabolite, or results that help to define a biomarker for a known clinical outcome. By presenting the results as we did, that is, limited to possible health implications for an individual participant, respondents' interest in receiving results might be enhanced. Secondly, our findings should be interpreted prudently, as differences in mean-scores, albeit significant, were very small and may be due to our large sample size. Thirdly, the Dutch Health Care Consumer Panel was not fully representative for the Dutch population, as participants of the panel were a bit older. Because older age is associated with wanting more information, our results may slightly over-represent the information preference of the general Dutch adult population. Moreover, we may say that participants of the panel have an interest in healthrelated issues in general, as they are willing to contribute to the panel, and may therefore also over-represent the information preference of the general Dutch population. Finally, in the panel as well as the group of patients, respondents that were employed in health care seem over-represented compared to the general Dutch working population [CBS, 2010]. Hence, respondents were probably more familiar with health issues than the general Dutch population.

\section{[TABLE 4]}

\section{[TABLE 5]}

\section{Communication Policy of Biobanks}

High information preference does not necessarily mean that individual results should be offered to participants, as also argued by Meyer [2008]. This conclusion seems to be supported by our respondents. Though many respondents indicated that they would like to receive various kinds of individual research results, fewer respondents were of the opinion that researchers have the duty to make this possible, especially in the case of individual results with no treatment available. However, a small majority did have the opinion that individual results should be offered regardless of health consequences. Of notice is the fact that there is a group who does not want to receive any results and who can be potentially harmed if they would receive information. Receiving results can motivate individuals to participate in largescale genetic cohort studies [Kaufmanet al., 2008]. Biobanks mostly only report results of measurements at enrolment and, sometimes, (unexpected) results that are of clinical significance. The question is if (potential) 
Meulenkamp, T.M., Gevers, S.K., Bovenberg, J.A., Koppelman, G.H., Hylckama Vlieg, A. van, Smets, E.M.A. Communication of biobanks' research results: what do (potential) participants want? American Journal of Medical Genetics: Part A: 2010, 152A(10), 2482-2492

participants of biobanks appreciate this policy, as expectations can be high(er). Dixon-Woods et al. [2007] found that 8 out of 29 people believed that they would receive individualized feedback on genetic analysis, despite an explanation that they would not get such information. In a study by Ormond et al. [2009]30\% of the participants of a biobank believed that they would learn which condition/diseases theywould develop, though they were explained that it would be extremely unlikely that they would be contacted with individual results. These and our results lead us to conclude that to manage (potential) participants' expectations, the communication policy of a biobank must be clear, open, and transparent and, most importantly, must be an ongoing process. Managing diversity remains important for participantswhoeither do notwant or who expect any information on research results.

\section{ACKNOWLEDGMENTS}

This article is the result of a research project of the Centre for Society and Genomics in the Netherlands, funded by the Netherlands Genomics Initiative. Genetic studies on asthma and rhinitis were supported by the Netherlands Asthma Foundation (grant 98.48 and 3.2.00.37). We are very grateful to the participants of the Dutch Health Consumer Panel and the patients who were willing to fill in the survey. We would like to thank Prof. Dr. D. Postma, Prof. Dr. F. Rosendaal, and Dr. L. Flinterman for their help in recruiting the patients for this study.

\section{REFERENCES}

Beskow LM, Burke W, Merz JF, Barr PA, Terry S, Penchaszadeh VB, Gostin LO, Gwinn M, Khoury MJ. 2001. Informed consent for population-based research involving genetics. JAMA 286:2315-2321. Bogardus ST, Holmboe E, Jekel JF. 1999. Perils, pitfalls, and possibilities in talking about medical risk. JAMA 281:1037-1041. Boggio A. 2008. Informing participants about research results. In: Elger B, BillerAndorno N, Mauron A, Capron AM, editors. Ethical issues in governing biobanks. Ashgate: Global Perspectives. pp. 189-196. Bovenberg JA, Meulenkamp T, Smets EM, Gevers S. 2009. Biobank research: Reporting results to individual participants. Eur J Health Law 16:229-247. Brodersen NH, Sutton S, Goff S, Hodgson SV, Thomas HJ. 2004. Anticipated reactions to genetic testing for hereditary non-polyposis colorectal cancer cancer susceptibility. Clin Genet 66:437-444. Cambon-Thomsen A. 2004. The social and ethical issues of post-genomic human biobanks. Nat Rev Genet 5:866-873. Cambon-Thomsen A, Rial-Sebbag E, KnoppersBM.2007. Trends in ethical and legal frameworks for the use of human biobanks. Eur Respir J 30:373-382. Cassileth BR, Zupkis RV, Sutton-Smith K, March V. 1980. Information and participation preferences among cancer patients. Ann Intern Med 92:832-836. CBS. 2010. Statline Statistics the Netherlands Databank. http://statline. cbs.nl/statweb/?LA=en. de Jong JD, van den Brink-Muinen A, Groenewegen PP. 2008. The Dutch health insurance reform: Switching between insurers, a comparison between the general population and the chronically ill and disabled. BMC Health Serv Res 8:58. Diergaarde B, Bowen DJ, Ludman EJ, Culver JO, Press N, Burke W. 2007. Genetic information: Special or not? Responses from focus groups with members of a health maintenance organization. Am J Med Genet Part A 143A:564-569. Dixon-Woods M, Ashcroft RE, Jackson CJ, Tobin MD, Kivits J, Burton PR, Samani NJ. 2007. Beyond "misunderstanding": Written information and decisions about taking part in a genetic epidemiology study. Soc Sci Med 65:2212-2222. Dugan E, Trachtenberg F, Hall MA. 2005. Development of abbreviated measures to assess patient trust in a physician, a health insurer, and the medical profession. BMC Health Serv Res 5:64. Edwards A, Elwyn G, Covey J, Matthews E, Pill R. 2001. Presenting risk information-A review of the effects of "framing" and other manipulations on patients outcomes. J Health Commun 6:61-82. Fernandez CV, Kodish E, Weijer C. 2003. Informing study participants of research results: An ethical imperative. IRB 25:12-19. Flinterman LE, van Hylckama Vlieg A, Rosendaal FR, Doggen CJ. 2008. Recurrent thrombosis and survival after a first venous thrombosis of the upper extremity. Circulation 118:1366-1672. Fong M, Braun KL, Chang RM. 2006. Native Hawaiian preferences for informed consent and disclosure of results from genetic research. J Cancer Educ 21:S47-S52. Franssen SJ, Lagarde SM, van Werven JR, Smets EMA, Tran KTC, Plukker JTM, van Lanschot JJB, de Haes HCJM. 2009. Psychological factors and preferences for communicating prognosis in esophageal cancer patients. Psychooncology 18:1199-1207. Hoeyer K, Olofsson BO, Mj€orndal T, Lyn€oe N. 2004. Informed consent and biobanks: A populationbased study of attitudes towards tissue donation for genetic research. Scand J Public Health 32:224-229. Janssen NB, Oort FJ, Fockens P, Willems DL, de Haes HC, Smets EM. 2009. Under what conditions do patients want to be informed about their risk of a complication? A Vignette Study. J Med Ethics 35:276- 
Meulenkamp, T.M., Gevers, S.K., Bovenberg, J.A., Koppelman, G.H., Hylckama Vlieg, A. van, Smets, E.M.A. Communication of biobanks' research results: what do (potential) participants want? American Journal of Medical Genetics: Part A: 2010, 152A(10), 2482-2492

282. Jongepier H, Koppelman GH, Nolte IM, Bruinenberg M, Bleecker ER, Meyers DA, te Meerman GH, Postma DS. 2005. Polymorphisms in SPINK5 are not associated with asthma in a Dutch population. J Allergy Clin Immunol 115:486-492. Kaphingst KA, Janoff JM, Harris LN, Emmons KM. 2006. Views of female breast cancer patients who donated biologic samples regarding storage and use of samples for genetic research. Clin Genet 69:393-398. Kaufman D, Murphy J, Scott J, Hudson K. 2008. Subjects matter: A survey of public opinions about a large genetic cohort study. Genet Med 10: 831-839. Knoppers BM, Joly Y, Simard J, Durocher F. 2006. The emergence of an ethical duty to disclose genetic research results: International perspectives. Eur J Hum Genet 14:1170-1178. Koppelman GH, te Meerman GJ, Postma DS. 2008. Genetic testing for asthma. Eur Respir J 32:775-782. MeyerMN.2008. The kindness of strangers: The donative contract between subjects and researchers and the non-obligation to return individual results of genetic research. Am J Bioeth 8:44-50. Michie S, Pinto J, Marteau T. 2005. Communicating risk information in genetic counseling: An observational study. Health Educ Behavior 32:589-598. Miller FG, Christensen R, Giacomini M, Robert JS. 2008. Duty to disclose what? Querying the putative obligation to return research results to participants. J Med Ethics 34(3):210-213. Murphy J, Scott J, Kaufman D, Geller G, LeRoy L, Hudson K. 2008. Public expectations for return of results from large-cohort genetic research.AmJ Bioeth 8:36-43. OngLM, VisserMR,van Zuuren FJ, Rietbroek RC, Lammes FB, de Haes JC. 1999. Cancer patients' coping styles and doctor-patient communication. Psychooncology 8:55-156. Ormond KE, Cirino AL, Helenowski IB, Chisholm RL, Wolf WA. 2009. Assessing the understanding of biobank participants. Am J Med Genet Part A 149A:188-198. Partridge AH, Winer EP. 2002. Informing clinical trial participants about study results. JAMA 288:363-365. Partridge AH, Burstein HJ, Gelman RS, Marcom PK, Winer EP. 2003. Do patients participating in clinical trials want to know study results? J Natl Cancer Inst 95:491-492. Partridge AH, Wong JS, Knudsen K, Gelman R, Sampson E, Gadd M, Bishop KL, Harris JR, Winer EP. 2005. Offering participants results of a clinical trial: Sharing results of a negative study. Lancet 365:963-964. Partridge AH, Wolff AC, Marcom PK, Kaufman PA, Zhang L, Gelman R, Moore C, Lake D, Fleming GF, Rugo HS, Atkins J, Sampson E, Collyar D, Winer EP. 2009. The impact of sharing results of a randomized breast cancer clinical trial with study participants. Breast Cancer Res Treat 115:123-129. Pearson TA, Manolio TA. 2008. How to interpret a genome-wide association study. JAMA 299:1335-1344. Pin RR. 2009. Development of a scale for health lifestyle. University of Twente, Faculty of Behavioural Sciences, Psychology and Communication of Health and Risk. Internal report. Postma DS, Meyers DA, Jongepier H, Howard TD, Koppelman GH, Bleecker ER. 2005. Genomewide screen for pulmonary function in 200 families ascertained for asthma. Am J Respir Crit Care Med 172: 446-452. Ravitsky V, Wilfond BS. 2006. Disclosing individual genetic results to research participants. Am J Bioeth 6:8-17. Reijmerink NE, Postma DS, Bruinenberg M, Nolte IM, Meyers DA, Bleecker ER, Koppelman GH. 2008. Association of IL1RL1, IL18R1, and IL18RAP gene cluster polymorphisms with asthma and atopy. J Allergy Clin Immunol 122:651.e8-654.e8. Rosendaal FR, van Hylckama Vlieg A, Doggen CJ. 2007. Venous thrombosis in the elderly. J Thromb Haemost 5:310-317. Schulz CJ, Riddle MP, Valdimirsdottir HB, Abramson DH, Sklar CA. 2003. Impact on survivors of retinoblastoma when informed of study results on risk of second cancers. Med Pediatr Oncol 41:36-43. Shalowitz DI, Miller FG. 2005. Disclosing individual results of clinical research: Implications of respect for participants. JAMA 294:737-740. Shalowitz DI, Miller FG. 2008. The search for clarity in communicating research results to study participants. J Med Ethics 34:e17. van Ommen GB, Cornel MC. 2008.

Recreational genomics? Dreams and fears on genetic susceptibility screening. Eur J Hum Genet 16:403404. van Zuuren FJ, de Groot KI, Mulder NL, Muris P. 1996. Coping with medical threat: An evaluation of the Threatening Medical Situations Inventory (TMSI). Person Individ Diff 21:21-31. Wakefield CE, Homewood J, Mahmut M, Taylor A, Meiser B. 2007. Usefulness of the Threatening Medical Situations Inventory in individuals considering genetic testing for cancer risk. Patient Educ Couns 69:29-38. Wendler D, Emanuel E. 2002. The debate over research on stored biological samples: What do sources think? Arch Intern Med 162:1457-1462. Wendler D, Pentz R. 2007. How does the collection of genetic test results affect research participants? Am J Med Genet Part A 143A:1733-1738. Wolf SM, Paradise J, Caga-anan C. 2008. The law of incidental findings in human subjects research: Establishing researchers' duties. J Law Med Ethics 36:361-383. 
Meulenkamp, T.M., Gevers, S.K., Bovenberg, J.A., Koppelman, G.H., Hylckama Vlieg, A. van, Smets, E.M.A. Communication of biobanks' research results: what do (potential) participants want? American Journal of Medical Genetics: Part A: 2010, 152A(10), 2482-2492

TABLES

\section{TABLE I. Sample Characteristics $(N=1,678)$}

$\begin{gathered}\text { Dutch health care } \\ \text { consumer panel } \\ (N=1,163)\end{gathered} \quad \begin{aligned} & \text { Patients } \\ & (N=515]\end{aligned}$

Sex

Male

$42.7 \%$

$45 \%$

Female

$57.3 \%$

$55 \%$

Age $^{\text {a }}$

Mean age [s.d.]

$55.7(14.1)$

$15.2 \%$

$50.3[13.5]$

18-40 years

$55.8 \%$

$24.4 \%$

40-65 years

$24.7 \%$

$60.1 \%$

65-80 years

$14.7 \%$

$>80$ years

$4.3 \%$

$0.8 \%$

Level of education

Primary school

$5.1 \%$

$6.9 \%$

Junior high school

$29.8 \%$

$29.3 \%$

Lower level vocational school

$24.1 \%$

$24.2 \%$

High school

$8.2 \%$

$7.7 \%$

University/advanced level

$32.8 \%$

$32.0 \%$ vocational school

Religious $^{\text {a }}$

$68.7 \%$

$54.6 \%$

Children

$82.8 \%$

$79.7 \%$

Ethnicity

Dutch

$99.1 \%$

$97.7 \%$

Other

Chronic illness ${ }^{c}$

$1.6 \%$

$4.1 \%$

$56.3 \%$

$57.8 \%$

Past or present contribution

$4.2 \%$

$100 \%$

to lasting health research

on genes and environment

Employed in healthcare

$27.0 \%$

$24.6 \%$

Involved with biotechnology

$4.4 \%$

$5.0 \%$

or genetics in work

${ }^{a}$ Significant difference between Dutch Health Care Consumer Panel and patients $(P<0.05)$.

bespondents could fill in more than one ethnicity.

'Percentage of patients who had another chronic illness (besides asthma, rhinitis, or thrombosis].

[TABLE 1] 
Meulenkamp, T.M., Gevers, S.K., Bovenberg, J.A., Koppelman, G.H., Hylckama Vlieg, A. van, Smets, E.M.A. Communication of biobanks' research results: what do (potential) participants want? American Journal of Medical Genetics: Part A: 2010, 152A(10), 2482-2492

[TABLE 2]

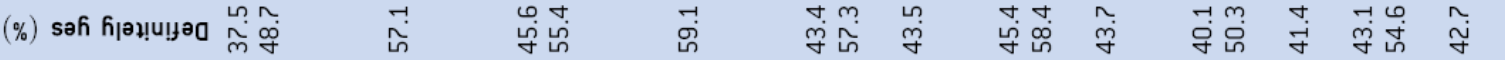

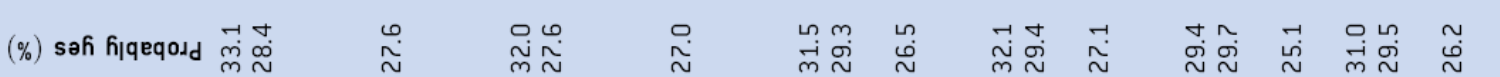

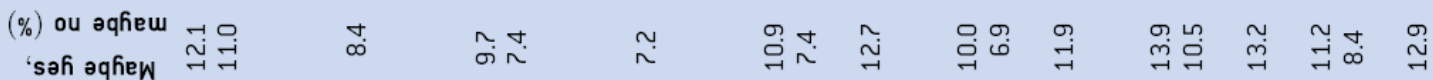

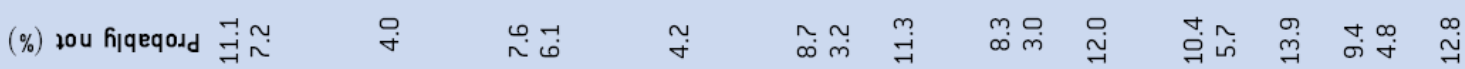

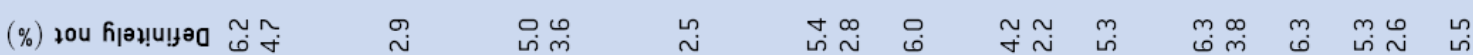

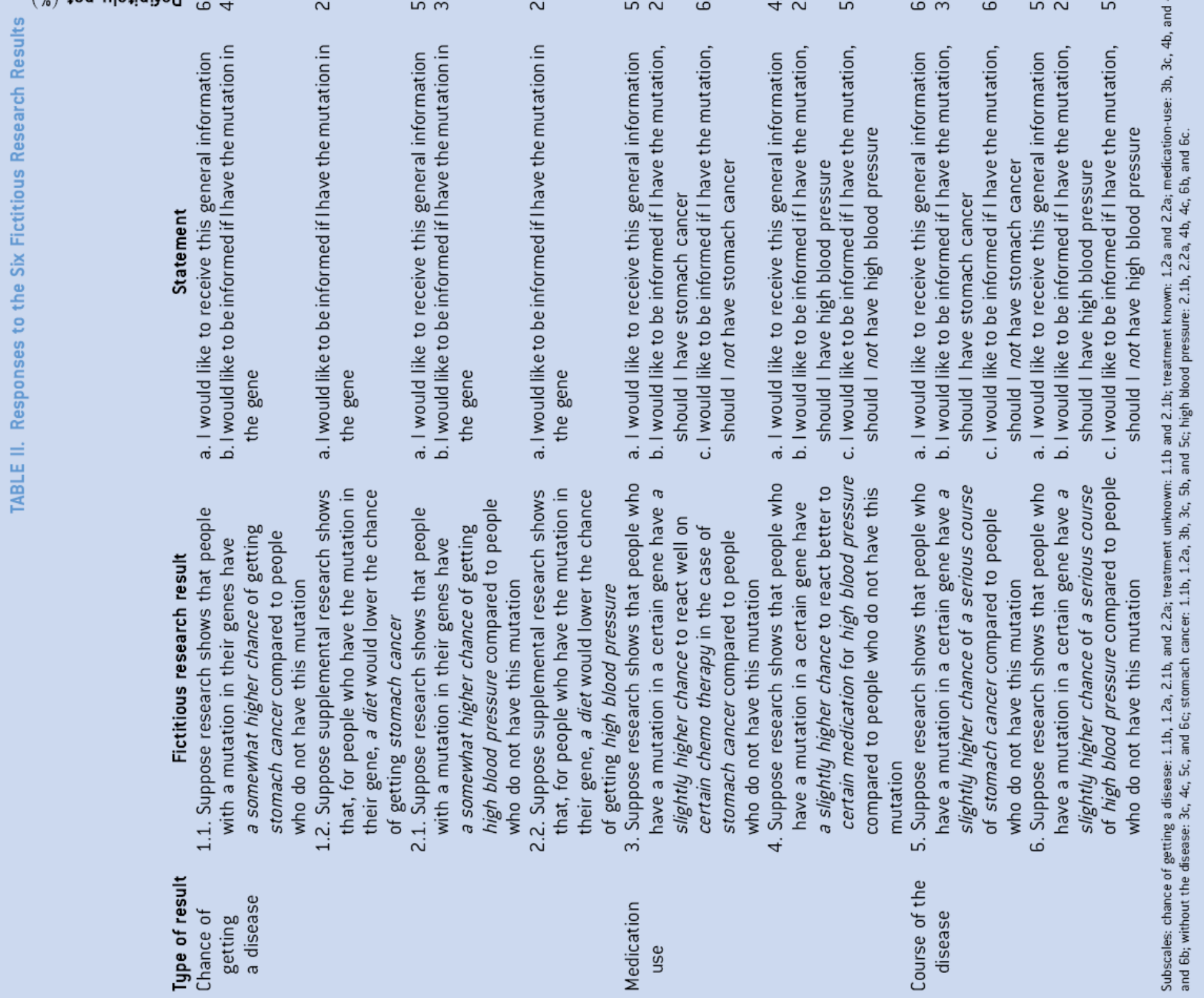


Meulenkamp, T.M., Gevers, S.K., Bovenberg, J.A., Koppelman, G.H., Hylckama Vlieg, A. van, Smets, E.M.A. Communication of biobanks' research results: what do (potential) participants want? American Journal of Medical Genetics: Part A: 2010, 152A(10), 2482-2492

\section{[TABLE 3]}

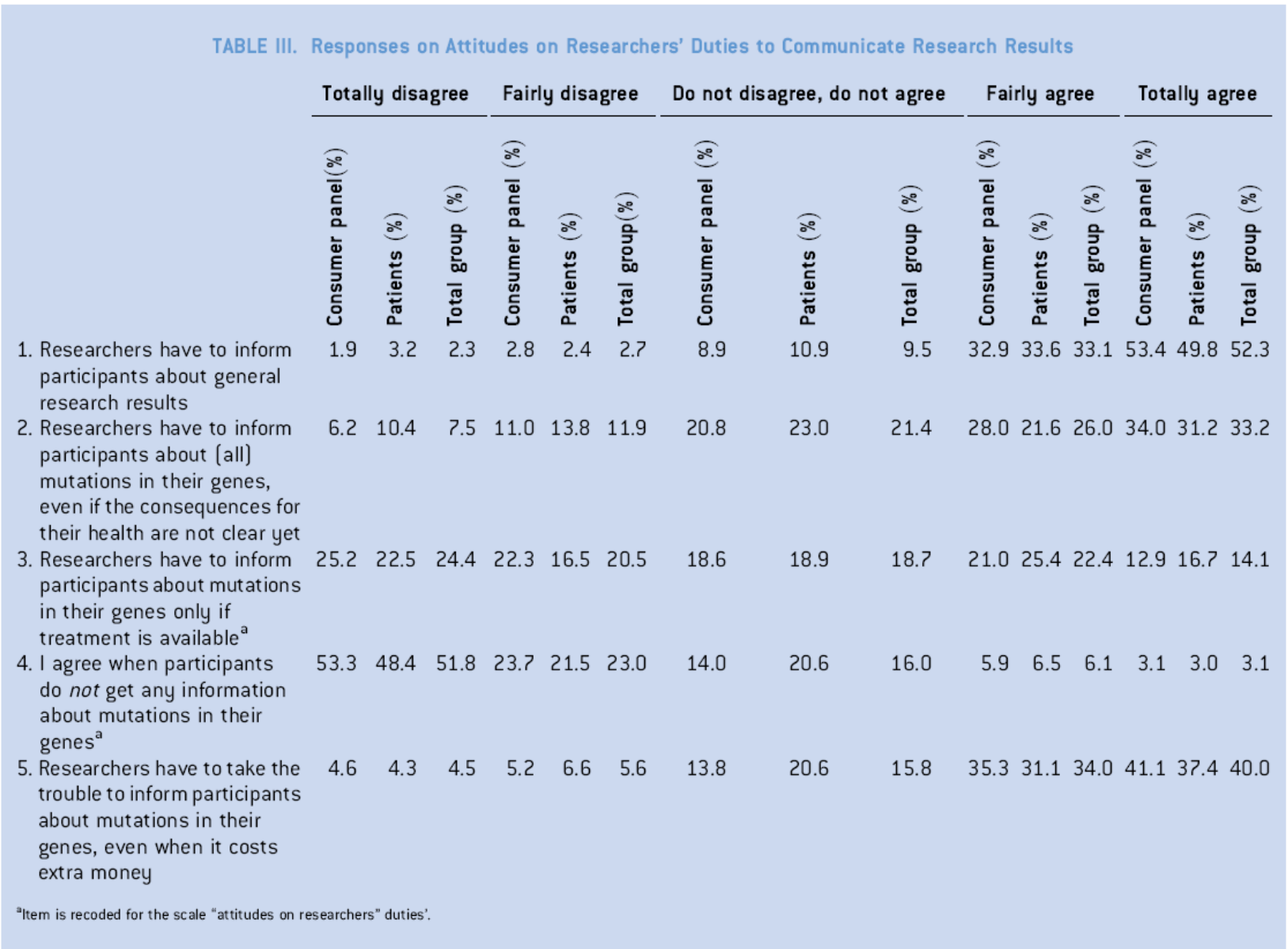

\section{[TABLE 4]}

TABLE IV. Factors Associated With Information Preference for Individual Results and Attitudes on Researchers' Duties to Communicate Research Results

Population [Dutch Health Care Consumer Panel or patients]

Gene-mutation information preference [adjusted $\mathrm{R}$ square $=0.280$ ] $\beta$ coeff $[\mathrm{SE}]$

Sociodemographic factors

Age

Sex $(0=$ male; $1=$ female $)$

Participation biobank

Reason participation "because the physician or researcher asks me"

Reason participation "health and treatment information"b

Psychological characteristics

Monitoring coping style

General desire for information about illnesses/treatment Attitudes related to biobanking

Advantage is that information can be meaningful for health children/family

Disadvantage is that information can frighten

Privacy will be harmed when information becomes available

Remain in control over blood after donation to biobank

$$
\begin{gathered}
\boldsymbol{\beta} \text { coeff }(\mathrm{SE}) \\
0.08(0.03)(P=0.001) \\
0.09[0.03)(P=0.001) \\
-0.08(0.03)(P=0.001) \\
0.07(0.03)(P=0.07) \\
0.13(0.03)(P<0.001) \\
0.18(0.03)(P<0.001) \\
0.33(0.03)(P<0.001) \\
-0.15(0.02)(P<0.001)
\end{gathered}
$$

Attitudes on researchers' duties

(adjusted $\mathrm{R}$ square $=0.249$ ] $\beta$ coeff (SE)$$
0.12(0.02)(P<0.001)
$$$$
-0.05[0.03)(P=0.047)
$$$$
0.1(0.02)(P<0.001)
$$$$
0.06(0.03)(P=0.026)
$$$$
0.16(0.03)(P<0.001)
$$$$
0.34(0.03)(P<0.001)
$$$$
-0.15(0.03)(P<0.001)
$$$$
-0.09(0.03)(P=0.001)
$$$$
0.09(0.03)(P=0.001)
$$

${ }^{2} 0$, because the physician or researcher asks me; 1 , altruistic.

0 , health and treatment information; 1 , altruistic.

[TABLE 5] 
Meulenkamp, T.M., Gevers, S.K., Bovenberg, J.A., Koppelman, G.H., Hylckama Vlieg, A. van, Smets, E.M.A. Communication of biobanks' research results: what do (potential) participants want? American Journal of Medical Genetics: Part A: 2010, 152A(10), 2482-2492

\section{TABLE V. Descriptive Information on Background Characteristics}

Health

Perceived health

Health-related lifestyle
Mean

3.0

25.5

0.9

4.1

Reason for [future) contribution to a biobank

1. To deliver a contribution to science

2. To get insight into own health

3. Maybe something will be found that contributes to the prevention or treatment of an illness where I, or my family, will be confronted with

4. I want to be meaningful for others, for instance for my children

5. Because the physician or researcher asks me

\section{Psychological characteristics}

Monitoring coping style

General information preference

General trust in physicians

Issues related to biobanking and communication of results

1. A person who donates blood for health research on genes and environment remains in control over his/her blood

2. My privacy will be harmed if information will become available about mutations in my genes

3. Information about mutations in my genes may negatively influence the height of the insurance premium

4. An advantage of information about mutation in my genes is that this information can be meaningful for the health of my children and/or family

5. A disadvantage of information about mutation in the genes is that this information may cause anxiety
Percentage

\begin{tabular}{|c|c|c|c|c|}
\hline Mean & SD & & \multirow{7}{*}{ 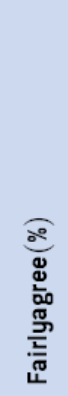 } & \multirow{7}{*}{ 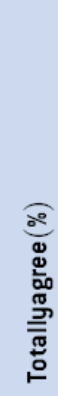 } \\
\hline 20.6 & 4.8 & & & \\
\hline 7.8 & 1.9 & & & \\
\hline 18.4 & 3.3 & & & \\
\hline \multicolumn{3}{|l|}{ ङ } & & \\
\hline 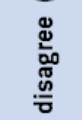 & 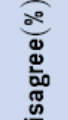 & 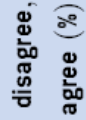 & & \\
\hline $\begin{array}{l}\text { D্ত } \\
\stackrel{\mathbb{J}}{\circ}\end{array}$ & 豙 & $\begin{array}{ll}\text { 늠 } & \text { 뭉 } \\
\text { 음 }\end{array}$ & & \\
\hline 21.0 & 17.0 & 20.1 & 21.2 & 20.7 \\
\hline 21.0 & 23.3 & 25.6 & 17.3 & 12.8 \\
\hline 12.8 & 8.1 & 30.7 & 27.7 & 20.7 \\
\hline 1.3 & 1.2 & 5.9 & 34.0 & 57.6 \\
\hline 4.0 & 5.4 & 13.5 & 45.1 & 32.1 \\
\hline
\end{tabular}

